\title{
Toxic Epidermal Necrolysis/Stevens-Johnson Syndrome at A University Hospital in Saudi: Causative Factors and Outcomes
}

Amal A Kokandi ( $\nabla$ akokandi@kau.edu.sa )

King Abdulaziz University

\section{Research Article}

Keywords: Stevens-Johnson syndrome, Toxic epidermal necrolysis, Drug reaction

Posted Date: January 14th, 2022

DOI: https://doi.org/10.21203/rs.3.rs-1222614/v1

License: (c) (i) This work is licensed under a Creative Commons Attribution 4.0 International License. Read Full License 


\section{Abstract}

Introduction:Toxic epidermal necrolysis (TEN) and Stevens-Johnson syndrome (SJS) are rare, life-threatening conditions caused mainly by drugs. Their management relies on the withdrawal of the culprit medication and supportive measures. Different pharmacotherapies have varied effects. However, data related to TEN and SJS in Saudi is limited. This study aimed to identify the causative agents, associated factors, and outcomes of TEN/SJS cases admitted to a teaching hospital (King Abdulaziz University) in Jeddah during the last 10 years.

Methods: We retrospectively analyzed the data of TEN/SJS patients admitted to the hospital over the last 10 years.

Results: We identified 12 patients with TEN/SJS. Of these, nine survived the condition and were discharged. The culprit medication was identified in eight of them, including antibiotics in six cases and Tegretol and allopurinol in one case each. Most of the patients received systemic steroids and intravenous immunoglobulins.

Conclusion: TEN/SJS is mainly caused by medications of which antibiotics are the most implicated. Consistent with other studies, the mortality rate associated with TEN/SJS in Saudi is $25 \%$. Limitations: restricted to a single center and small sample size.

\section{Key Summary Points}

1. As with previous studies, our study confirms that TEN/SJS is mainly caused by medications of which antibiotics are the most implicated.

2. Stopping offending medication and supportive therapy is important.

3. Mortality rate associated with TEN/SJS in Saudi is $25 \%$.

4. Systemic steroids and IVIG is still used extensively, other modalities are to be considered.

\section{Introduction}

Toxic epidermal necrolysis (TEN) and Stevens-Johnson syndrome (SJS) are rare, life-threatening conditions. They are usually caused by drug exposure and can be precipitated by viral infections, autoimmune diseases, and other unknown factors [1, 2]. Several medications are implicated in the onset of TEN/SJS, including antibiotics, non-steroidal anti-inflammatory drugs (NSAIDs), and anticonvulsants. The incidence of TEN/SJS is low worldwide, and there is a paucity of data on its epidemiology and causative agents in Saudi Arabi. There are 2 studies that collected data from other areas. These data can combine to form a cumulative data that help in improving our understanding of this disease.

A recent retrospective survey at the King Fahad Specialist Hospital (KFSH) in the Qassim region between January 2014 and January 2019 identified 10 patients with TEN/SJS, and one of them died [3]. The culprit medications included amoxicillin/clavulanic acid in three cases, carbamazepine in two, and acetaminophen, azithromycin, ciprofloxacin, and levetiracetam in one case each and an unknown cause in one case [3]. Another review of 13 patients diagnosed with TEN/SJS at the King Abdullah Medical City (KAMC), the Holy Makkah, between March 2003 and March 2010 revealed a mortality of 15\% (two patients) [4]. The medications associated with TEN were trimethoprim/sulphamethoxazole (TMP/SMZ) in four patients and amoxicillin/clavulanate, diclofenac sodium, ibuprofen, and phenytoin in one patient each. TMP/SMZ was implicated in a patient with SJS and one patient with an SJS/TEN syndrome overlap. Piroxicam and allopurinol were implicated in two patients with SJS/TEN overlap, and the last patient was receiving four drugs (phenytoin used for epilepsy for 30 years, metronidazole, allopurinol, and ibuprofen) at the time of diagnosis. Additionally, several case reports from different areas of Saudi have been published (Table 1). 


\begin{tabular}{|c|c|c|c|c|}
\hline Culprit medication & reference & $\begin{array}{l}\text { Treatment } \\
\text { used }\end{array}$ & outcome & Region \\
\hline $\begin{array}{l}3 \text { Amoxicillin/ Clavulonic acid, } 2 \text { Carbamazepine, } 1 \\
\text { Acetaminophen, Azithromycin, Ciprofloxacin, and Levetiracetam } \\
\text { and } 1 \text { of unknown cause }\end{array}$ & $\begin{array}{l}\text { Alajaji et } \\
\text { al, } 2020 \\
\text { [3] }\end{array}$ & $\begin{array}{l}\text { Steroids and } \\
\text { IVIG }\end{array}$ & $\begin{array}{l}9 \text { alive } \\
\text { and } 1 \\
\text { died }\end{array}$ & Qassim \\
\hline $\begin{array}{l}6 \text { trimethoprim/sulphamethoxazole (TMP/SMZ), } 1 \\
\text { amoxicillin/clavulanate, } 1 \text { ibuprofen, } 1 \text { diclofenac sodium, } 1 \\
\text { phenytoin, } 1 \text { Piroxicam and } 1 \text { allopurinol and } 1 \text { patient was } \\
\text { receiving } 4 \text { drugs at that time (phenytoin, metronidazole, } \\
\text { allopurinol, and ibuprofen) }\end{array}$ & $\begin{array}{l}\text { Nassar et } \\
\text { al, } 2010 \\
{[4]}\end{array}$ & $\begin{array}{l}\text { Steroids and } \\
\text { IVIG }\end{array}$ & $\begin{array}{l}11 \text { alive } \\
\text { and } 2 \\
\text { died }\end{array}$ & Makkah \\
\hline carbamazepine & $\begin{array}{l}\text { Wani et } \\
\text { al, } 2009 \\
\text { [5] }\end{array}$ & IVIG & alive & Makkah \\
\hline Possibly captopril & $\begin{array}{l}\text { Alkurtass } \\
\text { and Al- } \\
\text { Jazairi, } \\
2003[6]\end{array}$ & supportive & alive & Riyadh \\
\hline Co-Trimoxazole & $\begin{array}{l}\text { Suliman, } \\
2006 \text { [7] }\end{array}$ & supportive & alive & Tabuk \\
\hline Phenytoin & $\begin{array}{l}\text { AlQuliti } \\
\text { et al, } \\
2014[8]\end{array}$ & Hydrocortisone & Died & Dammam \\
\hline Lamotrigine & $\begin{array}{l}\text { Jan, } \\
2007 \text { [9] }\end{array}$ & & Died & Jeddah \\
\hline Cotrimoxazole ( 5 children) & $\begin{array}{l}\text { Elkharaz } \\
\text { et al, } \\
2006[10]\end{array}$ & $\begin{array}{l}\text { Hydrocortisone } \\
\text { and IVIG }\end{array}$ & alive & Unizah \\
\hline Cytomegalovirus infection & $\begin{array}{l}\text { Khalaf et } \\
\text { al, } 2011 \\
{[11]}\end{array}$ & IVIG & Died & AlKhobar \\
\hline Sildenafil (high dose) & $\begin{array}{l}\text { Al-Shouli } \\
\text { et al, } \\
2005 \text { [12] }\end{array}$ & infliximab & alive & Riyadh \\
\hline
\end{tabular}

This study aims to identify the causative agents, associated factors, and outcomes of TEN/SJS cases admitted to a teaching hospital (King Abdulaziz University) in Jeddah during the last 10 years.

\section{Materials And Methods}

This study retrospectively analyzed the data of patients diagnosed with TEN/SJS between 2011 and 2020. The study protocol was approved by the Unit of Biomedical Ethics Research Committee at King Abdulaziz University Hospital with a reference number: 529-20. As our hospital is a teaching hospital, all patients sign a informed consent upon admission to use their data for teaching and research purposes. The approvals were taken from the ethics committee and hospital affairs before collecting data. All methods are in accordance with the Declaration of Helsinki. All identifying information (names and ID numbers) were removed before analyzing data and none is represented in this report.

Data on all patients admitted with a TEN diagnosis (Lyell disease) and other related conditions (skin eruption due to drugs and medicaments, erythema multiforme, rash, and other nonspecific skin eruptions) were retrieved from the hospital electronic database and reviewed. The clinical data included the demographic data, length of stay in the hospital, culprit medications, associated comorbidities, treatment modalities, and outcomes. 
Results

After excluding one patient diagnosed with paraneoplastic pemphigus between January 1, 2011 and October 31, 2020, 12 patients were included in the study. Of these, nine were women, and three were men. The patients' ages ranged from 3 to 74 years (median 41 years). The culprit agents were antibiotics in 6 cases (trimethoprim/sulfamethoxazole, cefixime, ciprofloxacin in two cases and an unknown antibiotic in two cases), and Tegretol and allopurinol in one case each. Allopurinol was again suspected but not confirmed to be the cause in one case, while in the remaining three cases, the causative agent could not be identified (Table 2).

Table 2

Demographics of study patients:

\begin{tabular}{|c|c|c|c|c|c|c|c|c|}
\hline Case & Gender & Age & Weight & Dx & outcome & LOS* & Causative agent & Comorbidities \\
\hline 1 & $\mathrm{~F}$ & 31 & 102 & SJS & alive & 15 & unknown & $D M^{\star \star}$ \\
\hline 2 & $\mathrm{~F}$ & 31 & 80 & TEN & Died & 4 & $\begin{array}{l}\text { ? levofloxacin or } \\
\text { amoxicillin/ } \\
\text { clavulonic acid }\end{array}$ & $\begin{array}{l}\text { Severe mitral stenosis with } \\
\text { pulmonary hypertension and } \\
\text { aortic stenosis }\end{array}$ \\
\hline 3 & $M$ & 47 & 70 & TEN & alive & 27 & $\begin{array}{l}\text { Trimethoprim/ } \\
\text { sulfamethoxazole }\end{array}$ & \\
\hline 4 & $\mathrm{~F}$ & 74 & 56 & TEN & Died & 10 & Cefixime & 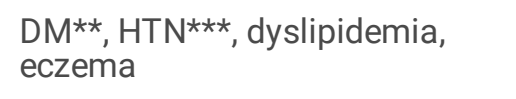 \\
\hline 5 & $\mathrm{~F}$ & 58 & 70 & SJS & alive & 13 & $\begin{array}{l}\text { ? antibiotic for } \\
\text { middle ear } \\
\text { infection }\end{array}$ & \\
\hline 6 & $M$ & 3 & 12 & SJS & alive & 17 & Tegretol & $\begin{array}{l}\text { shunted congenital } \\
\text { hydrocephalus and repaired } \\
\text { meningolcele, developmantaly 6- } \\
9 \text { months, sezures on } \\
\text { carbamazepine }\end{array}$ \\
\hline 7 & $\mathrm{~F}$ & 29 & 60 & TEN & Died & 78 & unknown & $\begin{array}{l}2 \text { weeks postpartum presented in } \\
\text { shock and skin lesions, } \\
\text { pancytopenia }\end{array}$ \\
\hline 8 & $\mathrm{~F}$ & 34 & 68 & TEN/SJS & alive & 6 & ciprofloxacin & $\begin{array}{l}\text { pregnant deliverd by CS } 6 \text { weeks } \\
\text { after episode, Hb } 5.9 \text { (refused } \\
\text { blood transfusion) }\end{array}$ \\
\hline 9 & $\mathrm{~F}$ & 35 & 56 & SJS & alive & 17 & ciprofloxacin & \\
\hline 10 & $\mathrm{~F}$ & 50 & 70 & SJS & alive & 2 & $\begin{array}{l}\text { ? allopuranol or } \\
\text { epagliflozin }\end{array}$ & $\mathrm{DM},{ }^{\star \star} \mathrm{HTN}^{\star \star \star \star}$, heart failure \\
\hline 11 & $\mathrm{~F}$ & 74 & 88 & TEN & alive & 38 & allopuranol & $\begin{array}{l}\text { HTN }{ }^{\star \star *} \text {, previous pulmonary } \\
\text { embolism on warfarin, heart } \\
\text { failure, thyroidictomy for thyroid } \\
\text { cancer }\end{array}$ \\
\hline 12 & M & 47 & 60 & TEN & alive & 6 & unknown & hepatitis B \\
\hline
\end{tabular}

The clinical diagnosis was TEN in six cases, SJS in five cases, and TEN/SJS overlap in one case. Nine patients survived the episode and were discharged, while the remaining three (patient numbers 2, 4, and 7) died (mortality rate of 25\%). Patient number 2 was a 31-year-old woman suffering from severe mitral stenosis with pulmonary hypertension and aortic stenosis. She had received two antibiotics (levofloxacin and amoxicillin/ clavulanic acid) simultaneously for a chest infection and was waiting for a valvular heart repair surgery. She died four days after admission. Patient number 4 was a 74-year-old woman with diabetes, hypertension, eczema, and hyperlipidemia. She died 10 days after admission. Patient number 7 was a 29-year-old woman who presented to the emergency department two weeks postpartum in shock, with extensive skin lesions and pancytopenia. She was 
admitted to the emergency room (ER), resuscitated, and transferred to the intensive care unit (ICU). After recovery and transfer to the medical ward, her condition deteriorated, and she died after 78 days.

All the patients in this study were treated in the ICU and received supportive therapy. They were referred based on clinical signs and symptoms and were assessed by medical internists, ophthalmologists, pulmonologists, dermatologists, gastroenterologists, gynecologists, or urologists. All of them, except two (patients 2 and 6), received systemic corticosteroids. One of them had severe mitral stenosis with pulmonary hypertension and aortic stenosis and eventually died. The other patient was a 3-year-old child with seizures. He had shunted congenital hydrocephalus and repaired meningocele and was developmentally 6-9 months. He recovered and was discharged. Intravenous immunoglobulin (IVIG) was used in nine cases. One patient who did not receive the immunoglobulins died. She was a 74-year-old woman with diabetes, hypertension, and eczema (Table 3). The dosage of immunoglobulins used varied between the patients (Table 3).

Table 3

Specific medications used for treatment:

\begin{tabular}{|c|c|c|c|c|c|c|c|}
\hline Case & outcome & IVIG given & $\begin{array}{l}\text { IVIG } \\
\text { dose } \\
(\mathrm{g} / \mathrm{kg})\end{array}$ & $\begin{array}{l}\text { Duration } \\
\text { (Days) }\end{array}$ & $\begin{array}{l}\text { total IVIG*/Kg } \\
\text { (gram) }\end{array}$ & Steroids & dose of steroid \\
\hline 1 & alive & $\begin{array}{l}42 \mathrm{~g} \mathrm{for} \\
5 \text { days }\end{array}$ & 0.4 & 5 & 2 & hydrocortisone & $\begin{array}{l}100 \mathrm{mg} \text { TID for } 3 \\
\text { days }\end{array}$ \\
\hline 2 & Died & $\begin{array}{l}250 \mathrm{~g} \text { for } 7 \\
\text { days }\end{array}$ & 3.125 & 7 & 21.88 & & \\
\hline 3 & alive & $\begin{array}{l}70 \mathrm{~g} \text { for } 3 \\
\text { days }\end{array}$ & 1 & 3 & 3 & methylprednisolone & $\begin{array}{l}60 \mathrm{mg} \text { BID for } 5 \\
\text { days }\end{array}$ \\
\hline 4 & Died & & & & & hydrocortisone/methylpred & $\begin{array}{l}100 \mathrm{mg} \text { for } 3 \\
\text { days/ } 1 \mathrm{~g} \text { stat }\end{array}$ \\
\hline 5 & alive & $\begin{array}{l}140 \mathrm{~g} \text { for } 3 \\
\text { days }\end{array}$ & 2 & 3 & 6 & hydrocortisone & $100 \mathrm{mg}$ for 1 day \\
\hline 6 & alive & $\begin{array}{l}5 \mathrm{~g} \text { for } 4 \\
\text { days }\end{array}$ & 0.42 & 4 & 1.67 & & \\
\hline 7 & Died & $\begin{array}{l}30 \mathrm{~g} \text { for } 7 \\
\text { days }\end{array}$ & 0.5 & 7 & 3.5 & hydrocortisone & $\begin{array}{l}100-200 \mathrm{mg} \text { daily } \\
\text { for several days }\end{array}$ \\
\hline 8 & alive & $\begin{array}{l}60 \mathrm{~g} \text { for } 3 \\
\text { days }\end{array}$ & 0.88 & 3 & 2.65 & hydrocortisone & $\begin{array}{l}100 \mathrm{mg} \text { for } 10 \\
\text { days }\end{array}$ \\
\hline 9 & alive & $\begin{array}{l}60 \mathrm{~g} \text { for } 3 \\
\text { days }\end{array}$ & 1.07 & 3 & 3.21 & prednisolone & $\begin{array}{l}20 \mathrm{mg} \text { for } 18 \\
\text { days }\end{array}$ \\
\hline 10 & alive & & & & & prednisolone & $50 \mathrm{mg}$ for 7 days \\
\hline 11 & alive & $\begin{array}{l}44 \mathrm{~g} \text { for } 5 \\
\text { days }\end{array}$ & 0.5 & 5 & 2.5 & methylprednisolone & $\begin{array}{l}\text { in emergency } \\
\text { department }\end{array}$ \\
\hline 12 & alive & & & & & methylpred/prednisolone & $60 \mathrm{mg}$ for 6 days \\
\hline
\end{tabular}

\section{Discussion}

TEN/SJS are severe mucocutaneous reactions triggered mainly by exposure to medications. In up to a third of the cases, no causative agent can be identified [1, 2]. Factors that increase the risk of this reaction include HIV infection, genetic factors, malignancy, high doses of medications, systemic lupus erythematosus, and some physical stimuli [13]. However, studies from Saudi are relatively few. In this retrospective study, we reviewed all TEN/SJS cases admitted to our hospital during the last 10 years. Antibiotics were confirmed to be the causative agents in four cases (ciprofloxacin in two, trimethoprim/sulfamethoxazole 
in one, and levofloxacin or amoxicillin/ clavulanic acid in one case) and were suspected but not confirmed in another two cases. Tegretol and allopurinol were implicated in one case each. For the remaining four cases, the causative agents were not identified (one of them was suspected to be allopurinol or empagliflozin). These findings are consistent with those of two previous studies from Saudi implicating antibiotics (including trimethoprim/sulphamethoxazole (TMP/SMZ), amoxicillin/clavulanate, and ciprofloxacin) as the most common cause of TEN/SJS [3, 4]. A previous study from Japan on 52 cases of SJS and 65 cases of TEN reported medications to be the causative agents in all the TEN cases and most SJS cases [14]. These included antibiotics, NSAIDs, anticonvulsants, and others. Mycoplasma pneumoniae and the antibiotics used to treat it are also known to cause TEN/SJS. A study involving a cohort of cancer patients found antibiotics (most frequently, trimethoprim/sulfamethoxazole), followed by anticonvulsants and antineoplastics agents, to be the most common inducers of TEN/SJS [15]. On the other hand, a study from China found anticonvulsants to be the most common causative agent followed by antibiotics [16]. A study by the Food and Drug Administration from the USA between July 2014 and December 2017 reported that antiepileptic medications were the most reported cause of TEN/SJS [17].

The first large case-control study (SCAR study) to assess TEN/SJS risk associated with exposure to medications was conducted in four European countries from 1989 to 1993. This study confirmed the high relative risk associated with antibiotics (especially cotrimoxazole, aminopenicillins, cephalosporins, quinolones, and cycline antibiotics), carbamazepine, phenytoin, phenobarbital, NSAIDs of the oxicam type, allopurinol, and chlormezanone [18]. A later case-control study (EuroSCAR study), which included 379 patients with SJS or TEN, and 1505 matched hospitalized controls [19], added more medications to the list of causative agents (lamotrigine and sulfasalazine, among others). Another study, including 66 patients and 28 control subjects, found allopurinol to be the most frequently associated drug with SJS or TEN [20].

Consistent with previous studies that have reported a 30\% mortality rate associated with TEN/SJS [21, 22], our study had a mortality rate of $25 \%$ ( 3 out of 12 patients died). All patients who died were diagnosed with TEN.

Supportive care is the most universally accepted strategy for the management of TEN/SJS [23]. Pharmacological therapy includes systemic corticosteroids, IVIG, cyclosporine [24, 25], and new inhibitors of tumor necrosis factor with varied effects. The use of plasmapheresis is equivocal, and thalidomide increases mortality [23]. A study from China comparing treatments based on the clinical outcomes in 39 cases of SJS and 48 cases of TEN found that increasing doses of corticosteroids did not influence the time taken to control SJS lesions but decreased the time taken to control TEN lesions. IVIG shortened the hospital stay for TEN and SJS and the time taken to control TEN [16]. A recent meta-analysis of 67 studies involving 2079 patients who received TEN treatment with immunomodulators concluded that IVIG in combination with corticosteroids could reduce the mortality in patients with TEN and SJS/TEN overlap. Thalidomide was found to be associated with a higher mortality rate [26]. Cyclosporine and etanercept emerged as promising therapies, but more studies are required to provide clearer evidence [26].

Our study has some limitations. First, it was restricted to a single center. The second is the small sample size. Finally, because of different coding, we might have missed on some TEN/SJS patients.

\section{Conclusions}

In conclusion, determining the most common causative agents for TEN/SJS in Saudi Arabia might help in the early prediction of the disease and could lead to preventive measures as cumulative data emerge from this region. These data will also help design a national initiative for the TEN/SJS registry.

\section{Declarations}

Funding: This research received no external funding.

Competing interests: The author declares no competing interests.

Data Availability: All patient data are available within the tables in the article and are available from corresponding author on reasonable request. 


\section{References}

1. Sassolas B, Haddad C, Mockenhaupt M, Dunant A, Liss Y, Bork K, et al. ALDEN, an algorithm for assessment of drug causality in Stevens-Johnson Syndrome and toxic epidermal necrolysis: Comparison with case-control analysis. Clin PharmacolTher. 88,60-68 (2021).

2. Chaby G, Ingen-Housz-Oro S, De Prost N, Wolkenstein P, Chosidow O, Fardet L. Idiopathic Stevens-Johnson syndrome and toxic epidermal necrolysis: Prevalence and patients' characteristics. J Am Acad Dermatol. 80, 1453-1455 (2019).

3. Alajaji A, Shekaran JC, Mohammed Aldhabbah OM, Alhindi HA, Almazyad NS, Aljutayli ZA, et al. Toxic epidermal necrolysis (TEN)/Stevens-Johnson Syndrome (SJS) epidemiology and mortality rate at King Fahad Specialist Hospital (KFSH) in Qassim region of Saudi Arabia: A retrospective study. Dermatol Res Pract. (2020).

4. Nassar A, Eid E, Bastawi Y, Kalakatawy M. Efficacy of intravenous immunoglobulins for treatment of Stevens-Johnson syndrome, toxic epidermal necrolysis and their overlap. Gulf Journal of Dermatology and Venereology. 17, 20-31 (2010).

5. Wani AM, Hussain WM, Fatani MI, Ali KS, Khoujah AM, Akhtar M, et al. Don't live in a town where there are no doctors: toxic epidermal necrolysis initially misdiagnosed as oral thrush. BMJ Case Rep. bcr10.2009.2392 (2009).

6. Alkurtass DA, Al-Jazairi AS. Possible captropril-induced toxic epidermal necrolysis. Ann Pharmacother. 37, $380-383$ (2003).

7. Suliman MT. Toxic epidermal necrolysis due to cotrimoxazole. Saudi Med J. 27, 109 (2006).

8. AlQuliti K, Ratrout B, AlZaki A. Antiepileptic drugs toxicity: A case of toxic epidermal necrolysis in patient with phenytoin prophylaxix post-cranial radiation for brain metastases. Saudi Pharm J. 22, 381-384 (2014).

9. Jan MM. Potentially serious Lamotrigine-related skin rash.Neurosciences (Riyadh). 12, 17-20 (2007).

10. Elkharaz S, Abdel-Razek EM, Eldin A, Abdel-Razek AM. Severe bullous skin diseases: analysis of seven children managed in a burns unit.Ann Burns Fire Disasters. 19, 180-187 (2006).

11. Khalaf D, Toema B, Dabbour N, Jehani F. Toxic epidermal necrolysis associated with severe cytomegalovirus infection in a patient on regular hemodialysis. Mediterr J Hematol Infect Dis. 3, e2011004 (2011).

12. Al-Shouli S, Abouchala N, Bogusz MJ, Al Tufail M, Thestrup-Pedersen K. toxic epidermal necrolysis associated with high intake of sildenafil and its response to infliximab. Acta DermVenereol. 85, 534-535 (2005).

13. High WA. Stevens-Johnson Syndrome and toxic epidermal necrolysis: Pathogenesis, clinical manifestations, and diagnosis. Available online: http://0o11270gv.y.https.www.uptodate.com.kau.proxy.deepknowledge.io/contents/stevens-johnsonsyndrome-and-toxic-epidermal-necrolysis-pathogenesis-clinical-manifestations-and diagnosis?

search=toxic\%20epidermal\%20necrolysis\&source=search_result\&selectedTitle=2 150\&usage_type=default\&display_rank=2 (accessed on 13-12-2020).

14. Yamane $Y$, Aihara M and Ikezawa Z. Analysis of Stevens-Johnson syndrome and toxic epidermal necrolysis in Japan from 2000 to 2006. Allergol Int. 56, 419-425 (2007).

15. Gillis NK, Hicks JK, Bell GC, Daly AJ, Kanetsky PA, McLeod HL. Incidence and triggers of Stevens-Johnson Syndrome and toxic epidermal necrolysis in a large cancer patient cohort. J Invest Dermatol. 137, 2021-2023 (2017).

16. Sun J, Liu J, Gong QL, Ding GZ, Ma LW, Zhang LC, et al. Stevens-Johnson Syndrome and toxic epidermal necrolysis: a multiaspect comparative 7-year study from the People's Republic of China. Drug Des DevelTher. 8, 2539-2547 (2014).

17. Borrelli EP, Lee EY, Descoteaux AM, Kogut SJ, Caffrey AR. Stevens-Johnson Syndrome and toxic epidermal necrolysis with antiepileptic drugs: An analysis of the food and drug administration adverse event reporting system (FAERS). Epilepsia. 59, 2318-2324 (2018).

18. Roujeau JC, Kelly JP, Naldi L, Rzany B, Stern S, Anderson T, et al. Medication use and the risk of Stevens-Johnson syndrome or toxic epidermal necrolysis. N Engl J Med. 333, 1600-1607 (1995).

19. Mockenhaupt M, Viboud C, Dunant A, Naldi L, Halevy S, Bouwes Bavinck JN, et al. Stevens-Johnson Syndrome and toxic epidermal necrolysis: Assessment of medication risks with emphasis on recently marketed drugs. The EuroSCAR-Study. $J$ Invest Dermatol. 128, 35-44 (2008).

20. Halevy S, Ghislain PD, Mockenhaupt M, Fagot JP, Bavinck JNB, Sidoroff A, et al. Allopurinol is the most common cause of Stevens-Johnson syndrome and toxic epidermal necrolysis in Europe and Israel. J Am Acad Dermatol. 58, 25-32 (2008). 
21. Schwartz RA, McDonough PH, Lee BW. Toxic epidermal necrolysis. Part II. Prognosis, sequelae, diagnosis, differential diagnosis, prevention, and treatment. J Am Acad Dermatol. 69, 187.e1-187.e15 (2013).

22. Sekula P, Dunant A, Mockenhaupt M, Naldi L, Bouwes Bavinck JN, Halevy S, et al. Comprehensive survival analysis of a cohort of patients with Stevens-Johnson syndrome and toxic epidermal necrolysis. J Invest Dermatol. 133, 1197-1204 (2013).

23. Schneider JA, Cohen PR. Stevens-Johnson Syndrome and toxic epidermal necrolysis: A concise review with a comprehensive summary of therapeutic interventions emphasizing supportive measures. Adv Ther. 34, 1235-1244 (2017).

24. Gilbert M, Scherrer LA. Efficacy and safety of cyclosporine in Stevens-Johnson syndrome and toxic epidermal necrolysis. Dermatol Ther. 32, e12758 (2019).

25. Kirchhof MG, Miliszewski MA, Sikora S, Papp A, Dutz JP. Retrospective review of Stevens-Johnson syndrome/ toxic epidermal necrolysis treatment comparing intravenous immunoglobulin with cyclosporine. J Am Acad Dermatol. 71, 941947 (2014).

26. Tsai TY, Huang IH, Chao YC, Li H, Hsieh TS, Wang HH, et al. Treating toxic epidermal necrolysis with systemic immunomodulating therapies: a systematic review and network meta-analysis. J Am Acad Dermatol. 84, 390-397 (2021). 